\title{
Coulisses
}

Revue de théâtre

25 | Hiver 2002

Varia

\section{1-2002 : changement et continuité au TUFC}

Extrait du rapport d'activités du TUFC

\section{Bernard Normand}

\section{(2) OpenEdition}

Journals

Édition électronique

URL : http://journals.openedition.org/coulisses/6090

DOI : $10.4000 /$ coulisses. 6090

ISSN : 2546-9460

Éditeur

Presses universitaires de Franche-Comté

\section{Édition imprimée}

Date de publication : 1 janvier 2002

Pagination : 116

ISBN : 2-84627-052-X

ISSN : $1150-594 \mathrm{X}$

Référence électronique

Bernard Normand, «2001-2002 : changement et continuité au TUFC », Coulisses [En ligne], 25 | Hiver 2002, mis en ligne le 24 octobre 2019, consulté le 15 novembre 2019. URL : http://

journals.openedition.org/coulisses/6090 ; DOI : 10.4000/coulisses.6090

Ce document a été généré automatiquement le 15 novembre 2019.

Coulisses 


\section{1-2002 : changement et continuité au TUFC}

Extrait du rapport d'activités du TUFC

Bernard Normand 
1 Depuis 1986, le Théâtre universitaire de Franche-Comté participe au développement du Théâtre amateur et de la vie culturelle à l'université de Franche-Comté.

Il permet l'accès à différentes pratiques théâtrales, favorise la (re)découverte de compagnies, d'auteurs, de textes et participe à une réflexion d'ensemble sur le théâtre, son esthétique et sa finalité. Le Théâtre universitaire de Franche-Comté souhaite ainsi contribuer à enrichir le champ culturel de ses usagers. Il ambitionne de susciter une envie plus fréquente d'aller à la rencontre du spectacle vivant et de découvrir la valeur du monde sensible. Parfois même, il suscite des vocations...

2 Dans cette perspective, chaque année il articule ses activités sur la base des missions qui font la spécificité de l'université : la formation, la recherche et la diffusion.

3 Au-delà de la ligne de force du Théâtre universitaire, qui fait l'objet d'une reconnaissance établie : la Création Collective, les objectifs de cette année 2001-2002 sont :

1. Le T.U.F.C., une association étudiante culturelle universitaire en collaboration avec d'autres associations de l'université ou d'autres établissements qui participent à la vie culturelle (par exemple : le Projet Aurore, l'École des Beaux-Arts et le Conservatoire régional).

2. Renforcer la présence des Rencontres internationales de théâtre universitaire dans notre environnement.

3. Un travail de fond avec un auteur dramatique de 1er rang: A. Gatti, qui se déroulera sur l'ensemble de l'année et qui se finalisera par une résidence-création en juillet et août 2002 sur le campus de la Bouloie.

Parce que Lucile Garbagnati cesse ses activités de présidente du Théâtre universitaire, cette année 2001-2002 correspond aussi à une année charnière pour notre structure. Le renouvellement du bureau de notre association est en effet l'occasion de montrer notre désir de pérenniser le fonctionnement de notre association.

\section{AUTEUR}

BERNARD NORMAND

Président du TUFC 